\title{
A STUDY OF THE DISTRIBUTION OF RHEUMATIC INFECTION IN CHILDREN IN BIRMINGHAM.
}

\author{
BY \\ A. P. THOMSON, M.D., M.R.C.P., \\ Assistant Physician, General Hospital, Birmingham. \\ Physician, Children's Hospital, Birmingham.
}

A preliminary investigation of the distribution of rheumatic infection in Birmingham during the years $1922-1926^{1}$ shewed that the great majority of cases occurred in houses situated along the courses of two streams running through the city. From this fact it was inferred that damp in dwelling-houses might have a powerful influence in predisposing towards rheumatic infection.

The establishment of a Rheumatism Bureau at the Children's Hospital under the care of the Lady Almoner, Miss N. J. Herald, has secured information concerning a larger number of cases. Including the four hundred children considered in the previous personal investigation the Bureau has now records of over 800 cases of rheumatic infection occurring in Birmingham in the period 1922-1927. Notifications of the cases have reached the Bureau mainly from the School Medical Service (by the kindness of Dr. G. A. Auden), and from the Staff of the Children's Hospital, both from the out-patient department and from the wards; a few have come from general practitioners.

I have satisfied myself that the notifications from the School Medical Service represent true cases of rheumatic infection : the majority of them were obvious instances either of chorea or carditis. The cases from the Children's Hospital can, of course, be accepted as definite : and those notified by general practitioners are also reliable; usually they have been children with severe carditis or chorea whom it has been impossible to control satisfactorily at home.

Since 1918 the housing shortage in Birmingham has been so severe that it has been impossible for the great majority of the working class population to move their homes and it may fairly be claimed that, as a rule, the houses in which rheumatic children were living at the time when they were notified to us were actually the houses in which they had acquired their disease. This contention could certainly be established up to the year 1925: since then removals may have introduced a fallacy, but $\mathrm{I}$ feel that it is only a slight one for we have been on our guard and have, as far as possible, enquired for recent changes of residence. 
A spot-map to shew the distribution of 805 cases in the city has been prepared (Fig. 1), and on the whole it supports the conclusion reached in my earlier study, namely, that the majority of the cases crop out along the two streams that pass through Birmingham. It is also clear that there is no distinct regional distribution of chorea and rheumatism : the cases are indiscriminately mixed.

The fact that in Birmingham the proximity of working-class houses to water courses is apparently associated with a heavy incidence of rheumatic infection does not of itself warrant the inference that a damp house is of importance in the causation of the disease. There are obvious sources of fallacy which require consideration. It is possible, for instance, that the rheumatic zones as shewn in the map by mere chance correspond either with the areas of densest population or with those of greatest poverty.

\section{Table.}

\begin{tabular}{|c|c|c|c|c|c|}
\hline \multirow{2}{*}{$\begin{array}{l}\text { Rheumatic } \\
\text { Incidence }\end{array}$} & \multirow{2}{*}{ Wards. } & \multirow{2}{*}{$\begin{array}{c}\begin{array}{c}\text { Total (notified) } \\
\text { case rate per } \\
1,000 .\end{array} \\
\begin{array}{c}\text { Rheumatic } \\
\text { Infection. } \\
1922-27\end{array}\end{array}$} & \multirow{2}{*}{$\begin{array}{l}\text { Population } \\
\text { per acre. }\end{array}$} & \multicolumn{2}{|c|}{$\begin{array}{c}\text { Annual case rate } \\
\text { per } 1,000 .\end{array}$} \\
\hline & & & & $\begin{array}{c}\text { Scarlet Fever } \\
1924-26\end{array}$ & $\begin{array}{l}\text { Measles. } \\
1917-19\end{array}$ \\
\hline $\begin{array}{l}\text { Very } \\
\text { High }\end{array}$ & $\begin{array}{l}\text { St. Martin's \& Deritend } \\
\text { Balsall Heath }\end{array}$ & $\begin{array}{l}2 \cdot 0 \\
1 \cdot 98\end{array}$ & $\begin{array}{r}109 \\
99\end{array}$ & $\begin{array}{l}1 \cdot 98 \\
1 \cdot 69\end{array}$ & $\begin{array}{l}14 \cdot 4 \\
12 \cdot 9\end{array}$ \\
\hline High & $\begin{array}{l}\text { Market Hall } \\
\text { Aston } \\
\text { St. Mary's } \\
\text { Ladywood } \\
\text { Yardley } \\
\text { All Saints }\end{array}$ & $\begin{array}{l}1 \cdot 4 \\
1 \cdot 2 \\
1 \cdot 2 \\
1 \cdot 1 \\
1 \cdot 1 \\
1 \cdot 0\end{array}$ & $\begin{array}{r}56 \\
79 \\
98 \\
100 \\
7 \\
87\end{array}$ & $\begin{array}{l}1 \cdot 41 \\
2 \cdot 00 \\
1 \cdot 87 \\
2 \cdot 18 \\
3 \cdot 12 \\
2 \cdot 14\end{array}$ & $\begin{array}{l}12 \cdot 0 \\
15 \cdot 6 \\
15 \cdot 3 \\
11 \cdot 3 \\
18 \cdot 4 \\
14 \cdot 1\end{array}$ \\
\hline Moderate & $\begin{array}{l}\text { Saltley } \\
\text { Small Heath } \\
\text { Sparkbrook } \\
\text { Washwood Heath } \\
\text { Rotton Park } \\
\text { Handsworth } \\
\text { Duddleston \& Nechells } \\
\text { Lozells } \\
\text { St. Bartholomew's } \\
\text { St. Paul's }\end{array}$ & $\begin{array}{l}0 \cdot 95 \\
0 \cdot 92 \\
0 \cdot 92 \\
0 \cdot 9 \\
0 \cdot 8 \\
0 \cdot 8 \\
0 \cdot 8 \\
0 \cdot 7 \\
0 \cdot 7 \\
0 \cdot 7\end{array}$ & $\begin{array}{l}28 \\
46 \\
60 \\
30 \\
65 \\
41 \\
73 \\
95 \\
67 \\
82\end{array}$ & $\begin{array}{l}1: 96 \\
1 \cdot 91 \\
2 \cdot 07 \\
1 \cdot 94 \\
2 \cdot 65 \\
1 \cdot 58 \\
1 \cdot 32 \\
1 \cdot 89 \\
2 \cdot 64 \\
1 \cdot 84\end{array}$ & $\begin{array}{l}12 \cdot 5 \\
14 \cdot 5 \\
14 \cdot 7 \\
12 \cdot 0 \\
15 \cdot 1 \\
12 \cdot 9 \\
18 \cdot 9 \\
15 \cdot 2 \\
16 \cdot 3 \\
15 \cdot 5\end{array}$ \\
\hline Slight & $\begin{array}{l}\text { Sparkhill } \\
\text { Acock's Green } \\
\text { Soho } \\
\text { Selly Oak } \\
\text { Sandwell } \\
\text { Harborne } \\
\text { King's Norton } \\
\text { Edgbaston } \\
\text { Moseley } \\
\text { Erdington South } \\
\text { Northfield North }\end{array}$ & $\begin{array}{l}0 \cdot 43 \\
0 \cdot 43 \\
0 \cdot 4 \\
0 \cdot 4 \\
0 \cdot 4 \\
0 \cdot 4 \\
0 \cdot 4 \\
0 \cdot 4 \\
0 \cdot 36 \\
0 \cdot 18 \\
0 \cdot 05 \\
0 \cdot 0\end{array}$ & $\begin{array}{r}10 \\
14 \\
39 \\
17 \\
14 \\
8 \\
8 \\
14 \\
10 \\
8 \\
11 \\
2\end{array}$ & $\begin{array}{l}1 \cdot 75 \\
1.89 \\
1 \cdot 19 \\
2.59 \\
1.40 \\
2.56 \\
2.06 \\
1.51 \\
1.52 \\
1.97 \\
2 \cdot 10 \\
1.57\end{array}$ & $\begin{array}{r}11 \cdot 9 \\
17 \cdot 8 \\
14 \cdot 5 \\
13 \cdot 9 \\
15 \cdot 6 \\
14 \cdot 5 \\
9 \cdot 6 \\
7 \cdot 9 \\
15 \cdot 7 \\
12 \cdot 8 \\
11.1 \\
16 \cdot 2\end{array}$ \\
\hline
\end{tabular}




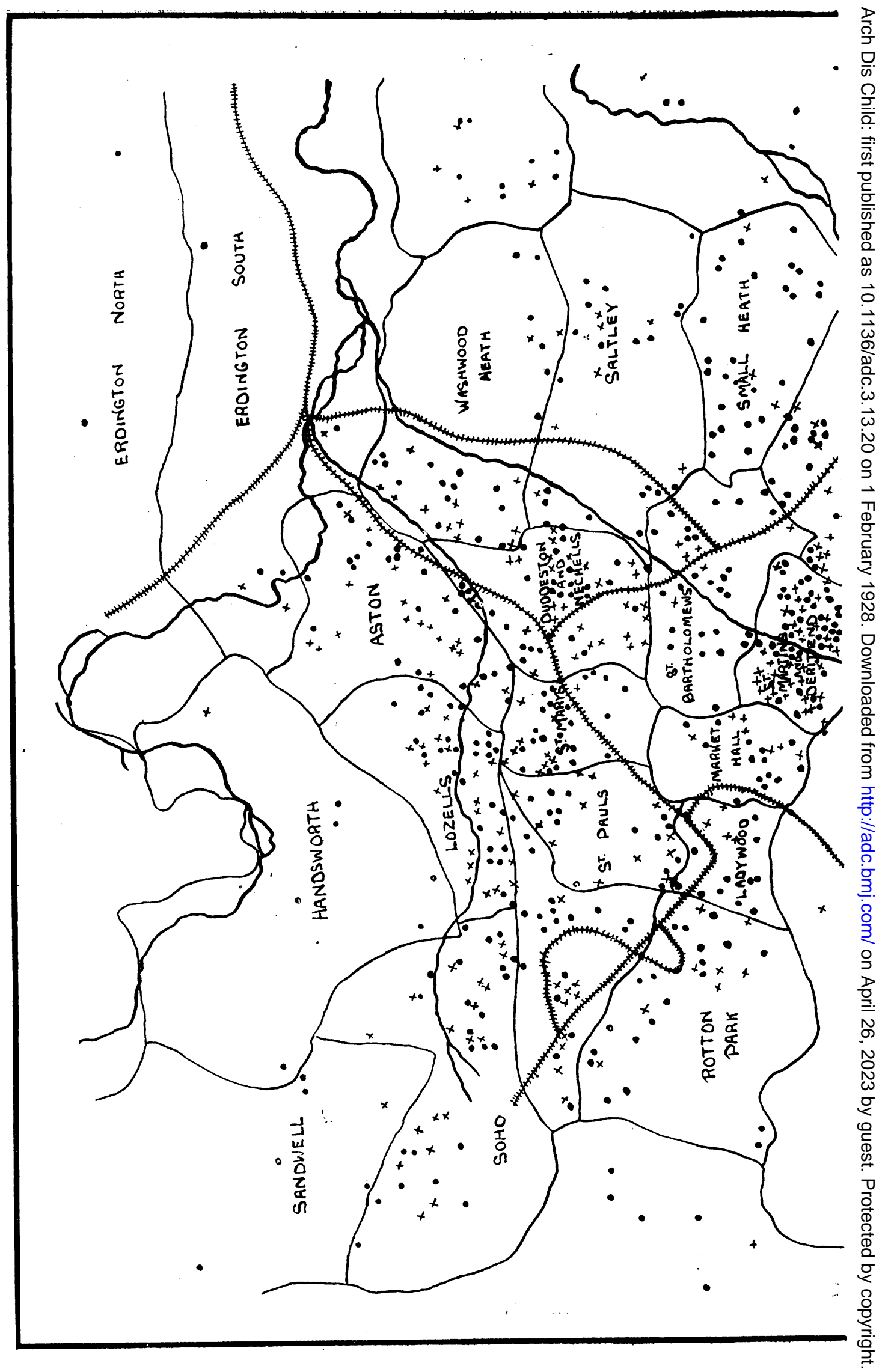




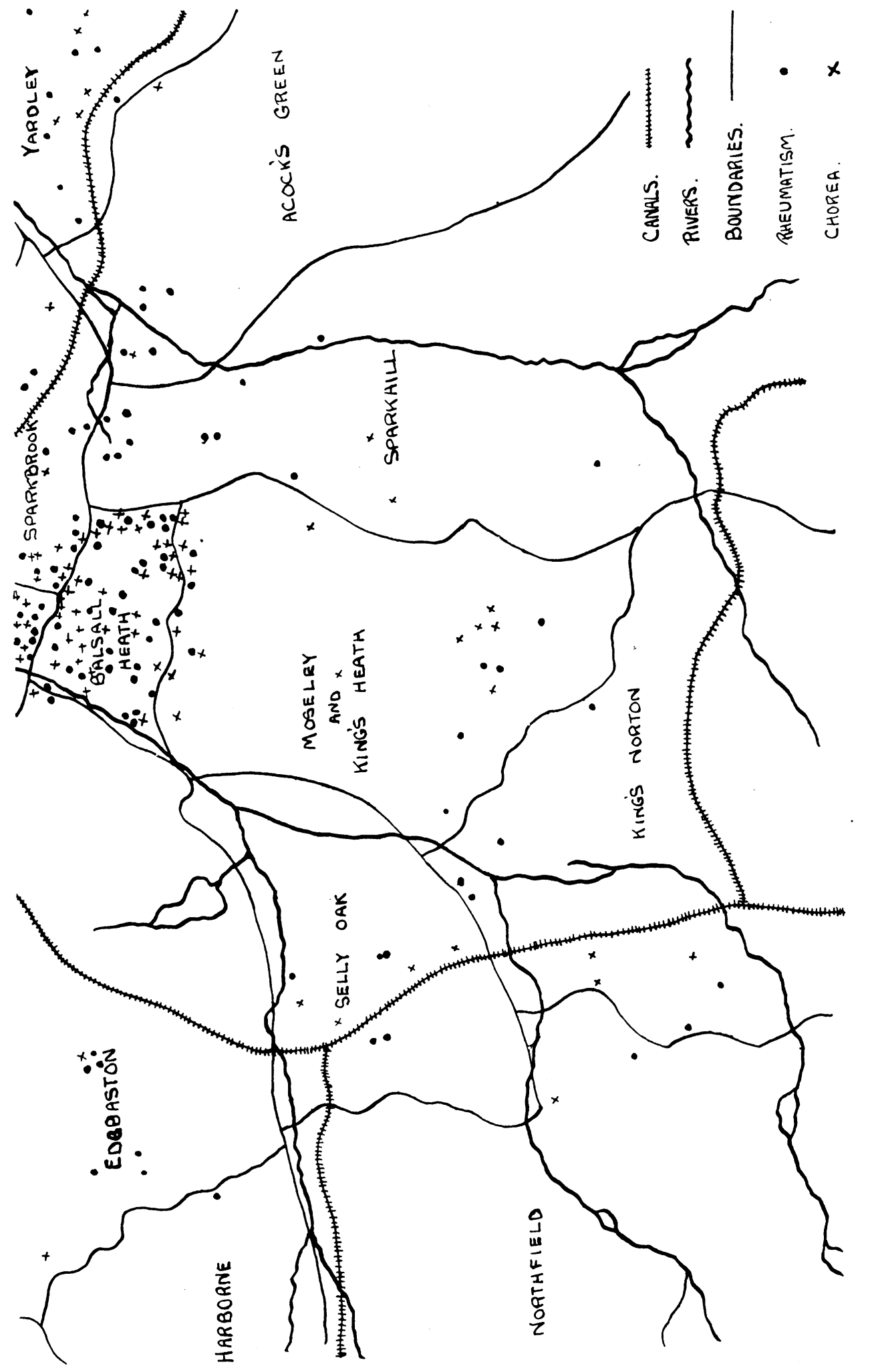

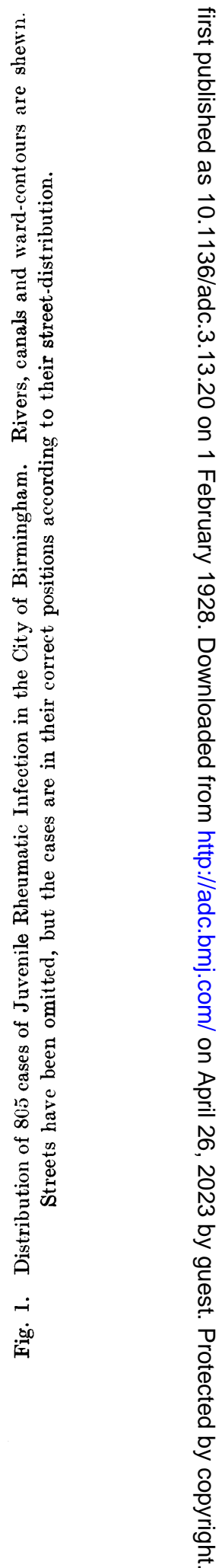




\section{The Influence of Density of Population.}

To explore the matter further I have prepared a table (p. 21), which shews the separate wards of the City of Birmingham together with the population per acre of each, and the total notified case-rate per 1000 of rheumatic infection during the years 1922-1927: in addition, for purposes of comparison records of the case-rates of measles and scarlet fever are included though, unfortunately, they are not available for the same years. I am indebted to Dr. W. H. Davidson, Senior Assistant Medical Officer of Health of Birmingham, for these figures.

Investigation of the distribution of a disease by studying its incidence in separate wards is not very satisfactory, for the divisions between the areas are purely arbitrary and a single ward may contain varied types of houses and social classes ; for these reasons a table of this kind must be cautiously used, particularly when, as in this instance, the cases considered are only a proportion of the total number. Nevertheless no other statistical method seemed possible.

The maximum notified case-rate per thousand of rheumatic infection in a single ward is 2 , and $\mathrm{I}$ have arbitrarily divided the table into four sections containing wards with very high $(2 \cdot 0-1 \cdot 5)$, high $(1 \cdot 5-1)$, moderate $(1-0.5)$, and slight $(0 \cdot 5-0)$ incidence of the disease.

There is on the whole a broad relationship between the incidence of rheumatism and density of population. Thus in the last section of wards with slight incidence there is none with dense population, and in the wards with very high and high degrees of rheumatic infection there is only one ward with sparse population (Yardley). It is clear, therefore, that the distribution of rheumatism among wards in the City of Birmingham supports the view that the prevalence of the disease is favoured by urban conditions and density of population. Study of the third group of wards, those with moderate incidence of rheumatic infection, indicates clearly, however, that some other factor, or factors, must play an important part, for there are included in it a number of wards in which, with a population as dense as that of the first two groups, the case-rates are much less. Why, for instance, should Lozells have one-half the rheumatic case-rate of Aston, and St. Mary's double that of St. Pauls? Saltley and Washwood Heath, again, are not densely populated and yet they have high rheumatic incidence.

It is further worth recording once more the fact that on investigating the housing conditions of an unselected group of rheumatic children in Birmingham I found no evidence of relative overcrowding; the figures were those common in the areas in which they lived.'.

\section{The Influence of Poverty.}

It is possible that degrees of poverty may be responsible for these curious variations and the matter deserves consideration despite the general impression derived from hospital practice, that the majority of rheumatic children do not 
belong to the destitute class. In his Annual Report for 1918, Sir John Robertson, the Medical Officer of Health for Birmingham, dealt particularly with the housing problem and one of his charts (Fig. 2) is here reproduced by his permission. This shews the relative distribution of back-to-back houses in the wards of the City. If this chart be taken as a fair indication of the degree of poverty existent in various areas, as I think it may, and if it be

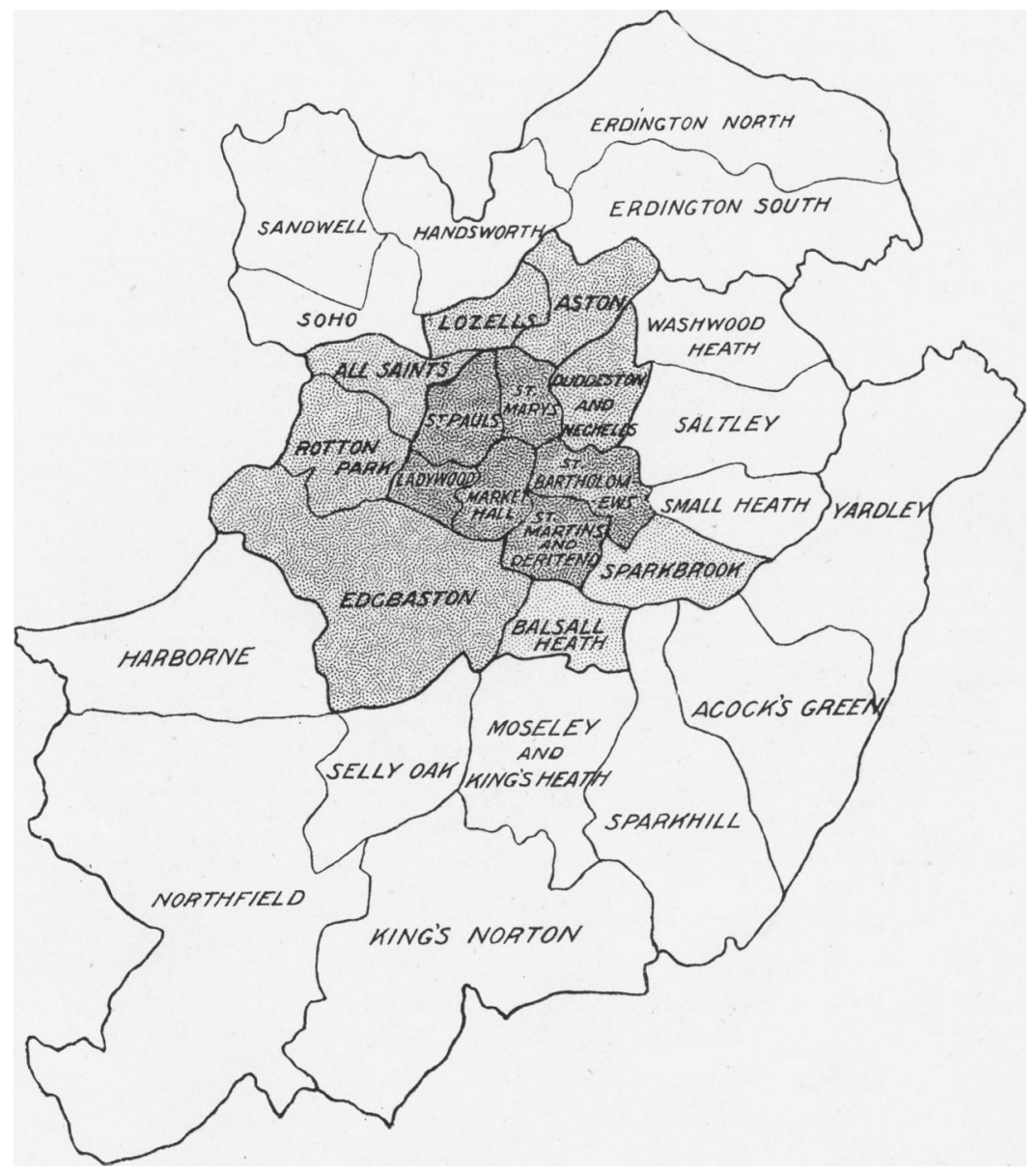

Fig. 2. PERCENTAGE OF BACK-TO-BACK HOUSES : CITY OF BIRMINGHAM, 1918.

$51-76$ per cent.
$27-47, "$,
$13-14,, \quad$,
$0 \cdot 1-8,, \quad$,


compared with one of a similar type (Fig. 3) to shew the notified case-rate of rheumatism it will be at once apparent that poverty and rheumatism are not closely associated in their distribution. Balsall Heath, a ward with relatively good housing has a great incidence of rheumatism; St. Paul's, one of the central ring of slum areas which strangle Birmingham, has only a moderate rheumatic case-rate.

\section{The Influence of other Infectious Diseases.}

It seemed possible that predisposition to rheumatism might be due to the ncidence of other infectious diseases. Reference to the table (p., 21 ) shews that,

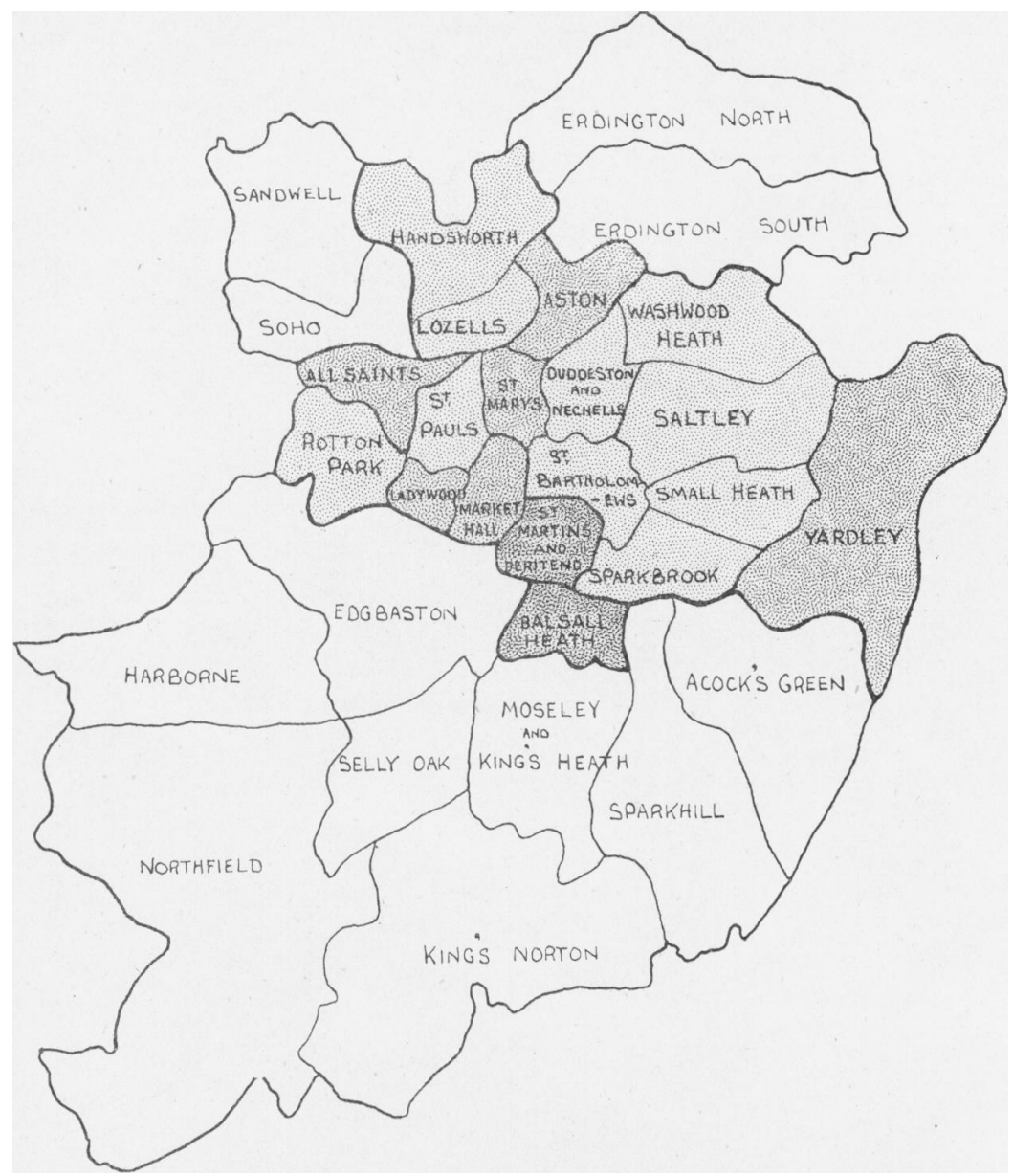

Fig.3. INCIDENCE OF RHEUMATIC INFECTION : 805 CASES IN THE WARDS OF THE CITY OF BIRMINGHAM, 1922-1927.

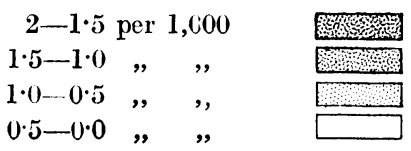


so far as figures are available, they give no support to this hypothesis in the case of scarlet fever and measles. The incidence of diphtheria (the figures for which were given to me by Dr. W. H. Davidson) is also not related.

\section{The Influence of Subsoil and Surface Water Level.}

The nature of the subsoil and the surface water level are matters of possible importance. Unfortunately it is very difficult in Birmingham to obtain information on these points and the matter is one for future investigation.

\section{Conclusions.}

The conclusion from this study, that neither density of population, nor poverty of housing, nor incidence of some other infectious diseases account satisfactorily for the variations of the rheumatic case-rate in different parts of the city, gives additional significance to the tentative opinion derived from the spot map (Fig. 1) that the situation of working-class houses close to water courses is of considerable importance. There are two points in connection with the map which merit consideration. First, the number of cases in Ladywood which is at some distance from the rivers is considerable. These cases represent in the main recent notifications to the Rheumatism Bureau of the Children's Hospital, itself situated in the middle of this area. It is possible, I think, that the large number of cases charted in this situation is due to the fact that delicate children in Ladywood are frequently taken direct to the hospital close by, and diagnosis and notification are in consequence likely to be more thorough and frequent. A fallacy of this kind is certainly possible when the system of notification is incomplete.

The second difficulty in accepting the view that the situation of the water courses largely determines the incidence of rheumatic infection is the fact that there are a large number of cases in part of Balsall Heath, towards Sparkbrook, which is well away from the river and also lies on high ground. The only hypothesis that occurs to me to account for this fact is that children in this area may be specially liable to infection by contact in schools with those living along the river banks.

\section{REFERENCE.}

1. Thomson, A. P., Birmingham Med. Rev. 1926, N.S., I. 1. 